\title{
Examining the Personality Traits and Empathetic Tendency Levels of Students of the Coaching Education Department
}

\section{Kazım Kaya ${ }^{1 \rtimes}$ \\ Çağrı Hamdi Erdoğan² Ziya Bahadir ${ }^{3}$ (iD}

'Kırşehir Ahi Evran University, College of Physical Education and Sports, Kırşehir, Turkey ${ }^{2}$ Ministry of Education, Cömlekçi Middle School, Kayseri, Turkey Email:erdoganhamdi@hotmail.com

${ }^{s}$ Erciyes University, Faculty of Sport Sciences, Kayseri, Turkey

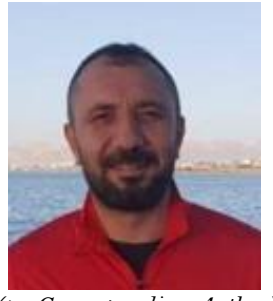

Corresponding Author

\section{Abstract}

The objective of this study is to determine the personality traits and empathetic tendency levels of students of the coaching education department. In addition to that, the empathetic tendency levels of students of the coaching education department were compared according to some characteristics. The research was conducted as a survey model. 347 students participated in the research group, who were studying at Erciyes University Department of Coaching Education, Faculty of Sport Sciences in the 2018-2019 academic year. In the study, Personal Information Form, Ten-Item Personality Inventory and Empathetic Tendency Scale were used as the data collection tools. SPSS program was used for the analysis of the data. According to the results of the study, the "compatible" personality trait of students of the coaching education department came to the fore and their empathetic tendency levels were determined at "medium level". Moreover, it was determined that there was statistically no significant difference in the empathetic tendency levels of students of the coaching education department concerning age, gender, academic grade, doing active sports, GPA, and sports branch.

Keywords: Coaching education, Personality, Empathic tendency, Student, Individuality, Sociability.

Citation | Kazım Kaya; Cağrı Hamdi Erdoğan; Ziya Bahadir (2019). Examining the Personality Traits and Empathetic Tendency Levels of Students of the Coaching Education Department. Asian Journal of Education and Training, 5(1): 255-259

History:

Received: 31 December 2018

Revised: 23 January 2019

Accepted: 20 February 2019

Accepted: 20 February 2019

Published: 15 March 2019

Attribution 3.0 License (cc) E

Publisher: Asian Online Journal Publishing Group
Contribution/Acknowledgement: All authors contributed to the conception and design of the study.

Funding: This study received no specific financial support

Competing Interests: The authors declare that they have no conflict of interests.

Transparency: The authors confirm that the manuscript is an honest, accurate, and transparent account of the study was reported; that no vital features of the study have been omitted; and that any discrepancies from the study as planned have been explained.

Ethical: This study follows all ethical practices during writing.

\section{Contents}

1. Introduction

3. Results.

References. 


\section{Introduction}

Empathy is putting oneself into someone's shoes and thus, understanding his/her feelings and opinions (Dökmen, 2009). Empathy is to see with someone else's eyes, to hear with someone else's ears, and to feel with someone else's heart (Adler, 1993). The empathy potential of an individual is explained through empathetic tendency concept. It is necessary to have the empathetic sensitivity for an individual to develop empathy (Akkoyun, 1987).

Personality is the reflection of the structure, which emerges as a result of the combination of certain innate biological and psychological features and interest, skill and talents of a person, upon behaviors and attitudes of an individual (İlal, 2001). Feelings, opinion, and patterns of behavior of individuals are determinants of their personality (Yavuzer, 2010).

An individual is called as coach who completes successfully his/her education programs in the relevant sport branch, gains necessary documents from the general directorates proving his/her level, and trains athletes or sports teams for competitions (GSGM, 2018). Coaching is accepted as a profession in our day; in this regard, "Coaching Education" departments are established in the universities, and courses and seminars are organized by relevant institutions, organizations and federations about coaching.

Coaches are sports trainers, who become a model for the athletes through their professional knowledge and personality traits, and it is expected that their behaviors should be displayed in accordance with the universally admitted and embraced values (Dolaşır, 2006). It is stated that coaches have a quite efficient role in the management of the game and the athletes (Ikizler, 2000).

It is considered critical that the coach candidates, who will work in different sports branches as a coach, have a good personality to be a model for the athletes and should display empathy towards their athletes. In this study, it was aimed to examine the personality traits and empathetic tendency levels of Coaching Education Department students, in other words, the coach candidates.

\section{Method}

\subsection{Research Model}

This is a survey model research aiming at examining the personality traits and empathetic tendency levels of students of the coaching education department. Survey model research studies are defined as the kind of studies, in which information is gathered from a large mass through multiple choice answers determined by the researcher (Fraenkel and Wallen, 2006).

\subsection{Research Group}

The research group was consisted of 347 students, who studied at the Department of Coaching Education in Faculty of Sport Sciences, Erciyes University during the 2018-2019 academic year, and they were selected through random sampling. 171 of the participant students were female (49.3\%), whereas 176 of them were male (50.7\%).

\subsection{Data Collection Tools}

As the data collection tools, a Personal Information Form that was developed by the researchers was used for collecting demographic characteristics of the students, a Ten-Item Personality Inventory was used for determining the personality traits of the students, and the Empathetic Tendency Scale was used for determining the empathetic tendency levels of the students.

Ten-Item Personality Inventory was developed by Gosling et al. (2003) this scale is comprised of 10 articles and five factors as "being open to experience", "responsibility", "being extravert", "compatibility", and "emotional balance". A seven point likert type, this scale has two articles for each sub-dimension. Each article includes two descriptors separated with a comma. The "being extravert" dimension in the scale involves some features such as being sociable, talkative, and social, the "compatibility " dimension involves being amiable, the "responsibility" dimension means being disciplined and task-oriented, the "emotional balance" dimension involves features such as having less anxiety and worry and being secure, while the "being open to experience" dimension involves features such as to have a liking for change and new experiences. The internal reliability coefficients of the sub-dimensions of the scale vary between 0.40 and 0.73 (Factor 1: 0.68, Factor 2: 0.40, Factor 3: 0.50, Factor 4: 0.73, Factor 5: $0.45)$.

Empathetic Tendency Scale was developed by Dökmen (1988) in order to measure the skills of individuals to develop empathy in the daily life. It is a five point likert type scale and it is comprised of 20 articles. The $3^{\text {rd }}, 6^{\text {th }}, 7^{\text {th }}$, $8^{\text {th }}, 11^{\text {th }}, 12^{\text {th }}, 13^{\text {th }}$ and $15^{\text {th }}$ articles of the scale are scored reversely. The lowest score in the Empathetic Tendency Scale is 20 points and the highest score is 100 points. If the score obtained from this one-dimensional scale is high it is concluded that the empathetic tendency is high as well, and if the score is low the tendency is low. The testretest reliability coefficient of the scale is .82 .

\subsection{Statistical Analyses}

Statistical analyses were conducted via SPSS program. In order to determine the personality traits and empathetic tendency levels of students of the coaching education department, arithmetic averages $(\overline{\mathrm{X}})$ and standard deviation $(\mathrm{Sd})$ were used among the descriptive statistics.

In the analyses, it was investigated through Kolmogorov-Smirnov Test whether the data followed a normal distribution. As a result, it was found that empathetic tendency levels did not follow normal distribution $(p=.000)$. Because of that, Mann-Whitney U Test was employed for paired comparisons and Kruskal Wallis Test for multiple comparisons. The accepted level of significance for all analyses was $\mathrm{p}<0.05$. 


\section{Results}

Table-1. Distribution of demographic characteristics of the students in the research group.

\begin{tabular}{l|c|c|c|c|c}
\hline Gender & $\mathbf{n}$ & $\mathbf{\%}$ & Academic Grade & $\mathbf{n}$ & $\mathbf{\%}$ \\
\hline Male & 176 & 50.7 & 1 st Grade & 96 & 27.6 \\
\hline Female & 171 & 49.3 & 2nd Grade & 105 & 30.3 \\
\hline Age & $\mathbf{n}$ & $\mathbf{\%}$ & 3rd Grade & 85 & 24.5 \\
\hline 18-20 Years old & 123 & 35.4 & 4 th Grade & 61 & 17.6 \\
\hline 21-23 Years old & 172 & 49.6 & Sport Branch & $\mathbf{n}$ & $\mathbf{\%}$ \\
\hline 24 Years old or over & 52 & 15 & Team Sports & 162 & 46.7 \\
\hline GPA & $\mathbf{n}$ & $\mathbf{\%}$ & Individual Sports & 185 & 53.3 \\
\hline Between 1.50-1.99 & 31 & 8.9 & Doing Active Sport & $\mathbf{n}$ & $\mathbf{\%}$ \\
\hline Between 2.00-2.49 & 99 & 28.5 & Yes & 252 & 72.6 \\
\hline Between 2.50-2.99 & 142 & 40.9 & No & 95 & 27.4 \\
\hline Between 3.00-3.49 & 75 & 21.7 & Total n: 347 & \\
\hline Sour P47
\end{tabular}

Source: Personal Information Forms with SPSS Analyze

According to the data obtained from the personal information forms, and as is seen on the Table 1, among the students in the research group, $176(50.7 \%)$ are male, $171(49.3 \%)$ are female; $123(35.4 \%)$ are 18 -20 years old, 172 $(49.6 \%)$ are $21-23$ years old, and $52(15 \%)$ are 24 years old or over. Of the students, $252(72.6 \%)$ are actively doing sports, 95 (27.4\%) don't do it actively; 31 (8.9\%) have GPAs between 1.50-1.99, 99 (28.5\%) have GPAs between 2.00-2.49, and the GPAs of $142(40.9 \%)$ are in between 2.50-2.99, while $75(21.7 \%)$ of them have GPAs between 3.00-3.49. Among the students, $96(27.6 \%)$ are $1^{\text {st }}$ grades, $105(30.3 \%) 2^{\text {nd }}$ grades, $85(24.5 \%) 3^{\text {rd }}$ grades, and 61 $(17.6 \%) 4^{\text {th }}$ grades; 162 of them $(46.7 \%)$ are doing team sports, while $185(53.3 \%)$ deals with individual sports.

Table-2. The averages that the students in the research group obtained from the ten-item personality inventory sub-dimensions and empathetic tendency scale in general.

\begin{tabular}{|c|c|c|c|}
\hline Personality and Empathetic Tendency & $\mathbf{n}$ & $\overline{\mathrm{X}}$ & Sd \\
\hline Being Extravert & 347 & 3.98 & 1.532 \\
\hline Compatibility & 347 & 4.71 & 1.252 \\
\hline Responsibility & 347 & 4.62 & 1.506 \\
\hline Emotional Balance & 347 & 4.20 & 1.084 \\
\hline Being Open to Experience & 347 & 4.47 & 1.301 \\
\hline Empathetic Tendency & 347 & 65.4 & .382 \\
\hline
\end{tabular}

The results revealed from the data obtained from the Ten-Item Personality Inventory sub-dimensions and Empathetic Tendency Scale are shown in Table 2. As is seen in the Table 2, the students in the research group obtained the following averages from the Ten-Item Personality Inventory sub-dimensions: Being Extravert $\bar{X}$ =3.98, Compatibility $\overline{\mathrm{X}}=4.71$, Responsibility $\overline{\mathrm{X}}=4.62$, Emotional Balance $\overline{\mathrm{X}}=4.20$ and Being Open to Experience $\overline{\mathrm{X}}=4.47$. According to these results, it can be mentioned that the "compatible" personality trait of students came to the fore among other traits with an average of $\bar{X}=4.71$. Moreover, it is observed that the students gained the average $\bar{X}=65.4$ from the Empathetic Tendency Scale in general. According to this result, the empathetic tendency levels of the students in the research group can be interpreted as "medium level".

Table-3. Comparison of the empathetic tendency levels of the students in the research group concerning gender, sport branch, and doing active sport.

\begin{tabular}{|c|c|c|c|c|c|c|}
\hline \multicolumn{2}{|c|}{ Characteristic } & $\mathbf{n}$ & Mean Rank & Sum of Ranks & $\mathbf{U}$ & p \\
\hline \multirow[t]{2}{*}{ Gender } & Male & 176 & 167.59 & 29496.50 & \multirow[t]{2}{*}{13920.500} & \multirow[t]{2}{*}{.227} \\
\hline & Female & 171 & 180.59 & 30881.50 & & \\
\hline \multirow[b]{2}{*}{ Sport Branch } & Team Sport & 162 & 172.48 & 27942.50 & \multirow[t]{2}{*}{14739.500} & \multirow[t]{2}{*}{.792} \\
\hline & Individual Sport & 185 & 175.33 & 32435.50 & & \\
\hline \multirow[t]{2}{*}{ Doing Active Sport } & Yes & 252 & 175.59 & 44248.50 & \multirow[t]{2}{*}{11569.500} & \multirow[t]{2}{*}{.630} \\
\hline & No & 95 & 169.78 & 16129.50 & & \\
\hline
\end{tabular}

Source: Empathetic Tendency Scale and Personal Information Forms with SPSS Analyze.

Table-4. Comparisons of the empathetic tendency levels of the research group students with regards to age, academic grade, and GPA.

\begin{tabular}{|c|c|c|c|c|c|c|}
\hline \multicolumn{2}{|c|}{ Characteristic } & $\mathbf{n}$ & Mean Rank & df & $\chi^{2}$ & $\mathbf{p}$ \\
\hline \multirow{3}{*}{ Age } & 18-20 Years old & 123 & 164.44 & \multirow{3}{*}{2} & \multirow{3}{*}{2.559} & \multirow{3}{*}{.278} \\
\hline & 21-23 Years old & 172 & 182.59 & & & \\
\hline & 24 Years old or over & 52 & 168.19 & & & \\
\hline \multirow{4}{*}{ Academic Grade } & $1^{\text {st }}$ Grade & 96 & 162.68 & \multirow{4}{*}{3} & \multirow{4}{*}{7.611} & \multirow{4}{*}{.055} \\
\hline & $2^{\text {nd }}$ Grade & 105 & 194.93 & & & \\
\hline & $3^{\text {rd }}$ Grade & 85 & 173.29 & & & \\
\hline & $4^{\text {th }}$ Grade & 61 & 156.77 & & & \\
\hline \multirow{4}{*}{ GPA } & Between 1.50-1.99 & 31 & 165.87 & \multirow{4}{*}{3} & \multirow{4}{*}{2.299} & \multirow{4}{*}{.513} \\
\hline & Between 2.00-2.49 & 99 & 164.66 & & & \\
\hline & Between 2.50-2.99 & 142 & 175.60 & & & \\
\hline & Between 3.00-3.49 & 75 & 186.67 & & & \\
\hline
\end{tabular}

Source: Empathetic Tendency Scale and Personal Information Forms with SPSS Analyze. 
The results of Mann-Whitney U Test, which was conducted for the paired comparisons of the abnormally distributed empathetic tendency levels of the research group students, are shown in Table 3. As is seen in Table 3, empathetic tendency levels of the research group students were compared with regards to gender, sport branch, and doing active sports; however, it was determined that there was statistically no significant difference.

The results of the Kruskal Wallis H Test, which was conducted for multiple comparisons of the abnormally distributed empathetic tendency levels of the students in the research group, are shown in Table 4. As is seen in Table 4, the empathetic tendency levels of the students in the research group were compared concerning age, academic grade, and GPA, and it was determined that there was statistically no significant difference.

\section{Discussion and Conclusion}

In this research study, the personality traits and empathetic tendency levels of students of the coaching education department were determined. Additionally, the empathetic tendency levels of students of the coaching education department were examined concerning some characteristics. According to the results of the study, the "compatible" personality trait of students of the coaching education department came to the fore and their empathetic tendency levels were determined at "medium level". Moreover, it was determined that there was statistically no significant difference in the empathetic tendency levels of students of the coaching education department concerning age, gender, academic grade, doing active sports, GPA, and sports branch.

In studies conducted by Kıvanç Sudak (2011); Tarhan (2012) and Ozer (2013) it was determined that the highest level personality trait in the participants was "compatible" personality trait. These mentioned studies are in parallel with this study. Akbulut and Sağlam (2010); Rehber and Atıcı (2009) determined that there was statistically significant difference in the empathetic tendency levels of the participants concerning gender. The results of abovementioned studies contradict to this study. Bulut and Düşmez (2014); Mutlu et al. (2015); Yaşar and Erol (2016) determined that there was statistically no significant difference in the empathetic tendency levels of the participants concerning gender. The results of these studies are in parallel with this research study. In different studies conducted by Günaydın (1999); Pınar (2004); Celik (2008); Mutlu et al. (2015); Yaşar and Erol (2016); Elik (2017) it was determined that there was statistically no significant difference in the empathetic tendency levels of the participants concerning age. The results of these studies are in parallel with this study. In other studies conducted by Genç and Kalafat (2008); Yılmaz and Akyel (2008); Tekin and Güllü (2010); Yaşar and Erol (2016) it was determined that there was statistically no significant difference in the empathetic tendency levels of the participants concerning academic grade. The results of these studies are in parallel with this study.

According to the findings of this study, it can be evaluated as a positive result that the "compatible" personality traits of students of the coaching education department came to the fore among others. Considering the future professions of students of the coaching education department, it can be thought that this result is more important than it seems. Increasing the participation of students of the coaching education department in social activities that enhance their positive personality traits might be useful for them. For further studies, examining the personality traits of students of the coaching education department on different research groups and with more participants can contribute to the literature.

According to the findings of this research study, it can be evaluated as a negative result that the empathetic tendency levels of students of the coaching education department were at "medium level". A development in the empathetic tendency levels of students of the coaching education department can be achieved through trainings provided by field experts. For further studies, examining the empathetic tendency levels of students of the coaching education department through qualitative research methods can make important contributions to the literature.

\section{References}

Adler, A., 1993. Psychological activity (translate in Turkish: Belkıs Çorakçı). İstanbul: Say Publications.

Akbulut, E. and H.İ. Sağlam, 2010. An investigation on levels of the emphatic tendencies of classroom teachers. Journal of Human Sciences, $7(2): 1068-1083$

Akkoyun, F., 1987. Empathic tendency and moral judgment. Journal of Psychology, 6(21): 91-92.

Bulut, H. and İ. Düşmez, 2014. Comparison of teachers' empathic tendency skills in terms of demographic and professional variables. Iğdır University Journal of Social Sciences, 5: 105-1 15.Available at: Iğdır University Journal of Social Sciences.

Celik, E., 2008. Investigation in terms of some variables of their empathy aptitude of preschool education teachers. Master's Thesis, Selçuk University, Institute of Social Sciences.

Dökmen, Ü., 1988. Measure empathy based on a new model and develop with psychodrama. Ankara University Faculty of Educational Sciences Journal, $21(1-2): 155-190$.

Dökmen, Ü., 2009. Communication conflicts in art and daily life, and empathy. 5th Edn., İstanbul: Remzi Publications.

Dolaşır, S., 2006. Ethics and principles of coaching. Ankara: Gazi Publications.

Elik, T., 2017. Sportsmen who play football as an amateur their sportsmensip trends and empathic tendencies in the Southeast Anatolia region. Master's Thesis, İstanbul Gelişim University, Health Sciences Institute.

Fraenkel, J.R. and N.E. Wallen, 2006. How to desing and evaluate research in education. New York: McGaw-Hill International Edition.

Genç, S.Z. and T. Kalafat, 2008. The evaluation of teacher candidates' democratic attitudes and emphatic skills. Journal of Social Sciences, 19(4): 54-66.

Gosling, S.D., P.J. Rentfrow and J.W.B. Swann, 2003. A very brief measure of the big-five personality domains. Journal of Research in Personality, 37(6): 504-528.Available at: https://doi.org/10.1016/s0092-6566(03)00046-1.

GSGM, 2018. Republic of Turkey, general directorate of sports, coaches education regulation, internet. Available from http://sporegitim.sgm.gov.tr/Sayfalar/2873/2859/Yonetmelikler.aspx [Accessed 11.12.2018].

Günaydın, M., 1999. A study at the sight of same variation of the teachers who work in middle training association levels of empathic and conflictional tendency. Master's Thesis, Ondokuz Mayıs University, Institute of Social Sciences.

Ikizler, H.C., 2000. Social sciences in sports. İstanbul: Alfa Publications.

İlal, G.K., 2001. Behavioral sciences medical psychology. İstanbul: Nobel Medicine Publications.

Kıvanç Sudak, M., 2011. A research on relationship between personality types emotional intelligence job satisfaction and organizational citizenship behaviour. Doctoral Dissertation, Gebze Technical University, Institute of Social Sciences.

Mutlu, O., E. Şentürk and E. Zorba, 2015. Empathic tendency of university students in tennis and communication skills. International Journal of Science Culture and Sport, 2(1): 129-137.

Ozer, E., 2013. An investigation of universty students' resilience level on the view of trait emotional eq and the five factor personality traits. Doctoral Dissertation, Necmettin Erbakan University, Institute of Educational Sciences. 
Pınar, G., 2004. Investigation of empathy levels of midwives/nurses working in delivery halls. Master's Thesis, Ege University, Health Sciences Institute.

Rehber, U. and Y. Atıcı, 2009. Examining the conflict resolution behaviors of students at the second stage of primary school according to their empathetic tendency levels. Çukurova University Journal of the Institute of Social Sciences, 18(1): 323-342.

Tarhan, S., 2012. The prediction of hope from self efficacy perceived social support and personality traits. Doctoral Dissertation, Gazi University, Institute of Educational Sciences.

Tekin, M. and M. Güllü, 2010. Analysis of empathic artifice level of teacher candidates who study in the school of physical education and sport. Procedia-Social and Behavioral Sciences, 2(2): 1987-1992.Available at: https://doi.org/10.1016/j.sbspro.2010.03.269.

Yaşar, M. and A. Erol, 2016. Determination of relationship between the empathic tendency levels and thinking styles of preschool teacher candidates. International Journal of Assessment Tools in Education, 2(2): 38-65.

Yavuzer, H., 2010. School of marriage. İstanbul: Remzi Publications.

Yllmaz, İ. and Y. Akyel, 2008. Examination of empatic tendency levels of physical education candidates teacher in terms of different variables. Journal of Kırşehir Education Faculty, 9(3): 27-33. 